\title{
La antropología amazónica de cara a la cuarta revolución industrial
}

\section{Fernando Santos Granero}

(iD) https://orcid.org/0000-0002-5049-8439

Smithsonian Tropical Research Institute

santosf@si.edu

RESUMEN

En este artículo, que reproduce la ponencia magistral presentada en setiembre de 2019 con motivo de los cincuenta años del curso de Antropología Amazónica en la Facultad de Ciencias Sociales de la Pontifica Universidad Católica del Perú, el autor propone que, a partir de la década de 2010, los pueblos indígenas amazónicos se han visto enfrentados a una nueva ola de cambio, esta vez, vinculada a lo que el economista Klaus Schwab (2016) ha denominado la «cuarta revolución industrial». Su objetivo no es, sin embargo, discutir las ventajas y desventajas de esta nueva revolución industrial, sino explorar cuáles son las nuevas direcciones que podría tomar la antropología amazónica a la luz de esta nueva ola de cambio. Para ello el autor explora seis grandes líneas de investigación, proponiendo para cada una de ellas una serie de preguntas dirigidas a fomentar u orientar investigaciones futuras.

Palabras clave: antropología amazónica, cuarta revolución industrial, cambio, nuevas líneas de investigación 


\section{Amazonian anthropology facing the fourth industrial revolution}

\section{ABSTRACT}

In this article, which reproduces the keynote talk presented in September 2019 on the occasion of the 50 th anniversary of the Amazonian Anthropology course at the Faculty of Social Sciences of the Pontifical Catholic University of Peru, the author proposes that, from the decade of 2010, Amazonian indigenous peoples have been faced with a new wave of change, this time linked to what the economist Klaus Schwab (2016) has called the "fourth industrial revolution». Its objective is not, however, to discuss the advantages and disadvantages of this new industrial revolution, but to explore what are the new directions that Amazonian anthropology could take in the light of this new wave of change. To this end, the author explores six major lines of research, proposing for each of them a series of questions aimed at promoting or guiding future research.

Keywords: Amazonian anthropology, fourth industrial revolution, change, new lines of research 
En 1996, hace más de veinte años, escribí en la introducción al volumen Globalización y cambio en la Amazonía indígena que los pueblos indígenas amazónicos habían pasado por dos grandes olas de cambio y que, desde la década de 1980, venían enfrentándose a una tercera ola de cambio como producto del proceso de globalización (Santos Granero, 1996). La primera ola de cambio, resultante del encuentro colonial, habría afectado a todos los pueblos indígenas de la cuenca amazónica, incluyendo a aquellos que nunca estuvieron en contacto directo con los conquistadores europeos. Como resultado, estos pueblos experimentaron fuertes procesos de disminución demográfica, desplazamiento territorial, pérdida de autonomía política y desarticulación étnica, pero también un importante proceso de transformación tecnológica, gracias a la adopción de herramientas y otros objetos de metal, los cuales revolucionaron sus actividades productivas, redes de intercambio y cultura material. Estos cambios ocasionaron el colapso de las sociedades ribereñas más complejas, la desaparición de muchos pueblos indígenas, la reformulación o surgimiento de nuevas identidades étnicas y el desarrollo de nuevas prácticas sociales, económicas y culturales que podrían ser denominadas como «neotradicionales».

La segunda ola de cambio, derivada del proceso de expansión capitalista, comenzó a darse en la segunda mitad del siglo XIX con el inicio del boom gomero y se profundizó a partir de 1940, a medida que los países amazónicos empezaron a impulsar grandes proyectos de colonización de sus regiones tropicales. Esta segunda ola ocasionó una nueva disminución demográfica, la invasión y despojo de los territorios indígenas, el quiebre de las redes de intercambio de larga distancia, una mayor dependencia económica como resultado de la generalización del sistema de habilitación y enganche, y un doble proceso de fragmentación intraétnica y de aislamiento interétnico. A partir de la década de 1960, y como resultado del mayor grado de integración en sus respectivas sociedades nacionales y la aparición de nuevos movimientos sociales, los pueblos indígenas amazónicos comenzaron a desarrollar sus propios proyectos económicos como productores independientes, a formar las primeras organizaciones políticas de nivel étnico 
y supraétnico, a plegarse a una variedad de iglesias cristianas no católicas y a incorporarse masivamente en el sistema nacional de educación formal. Como resultado de todos estos procesos, se abandonaron muchas prácticas rituales, se generalizó el alfabetismo y el bilingüismo y se perdió gran parte de la cultura material neotradicional, salvo en aquellos casos en que aquella fue reorientada hacia el mercado turístico.

La tercera ola de cambio tuvo sus comienzos en la década de 1980, junto con el proceso de globalización. Impulsado por la liberalización del comercio internacional, la proliferación de las empresas multinacionales, el crecimiento de las inversiones transfronterizas y la aparición de tecnologías digitales de información, dicho proceso ha resultado en una mayor interacción transnacional entre individuos, empresas, gobiernos, medios de comunicación y productores culturales. En la Amazonía indígena, el proceso de globalización generó las condiciones para el surgimiento de organizaciones etnopolíticas multinacionales, tales como la Coordinadora de las Organizaciones Indígenas de la Cuenca Amazónica (COICA), fundada en 1984. Resultó, asimismo, en una mayor visibilidad de los pueblos indígenas en el escenario internacional. Esto llevó a las Naciones Unidas a crear el Grupo de Trabajo sobre Poblaciones Indígenas en 1982 y a la Organización Internacional del Trabajo a adoptar el Convenio 169 sobre pueblos indígenas y tribales en 1989.

Estos tres elementos - mayor movilización etnopolítica, mayor visibilidad y mayor apoyo internacional — han favorecido a los pueblos indígenas. En efecto, presionados por las organizaciones indígenas y la opinión pública nacional e internacional, los países amazónicos se han visto obligados a reconocer los derechos territoriales de los pueblos indígenas amazónicos y titular, en algunos casos, grandes extensiones en su favor. La exportación de productos orgánicos o ecoamistosos para el mercado internacional, la implementación de proyectos de ecoturismo y el surgimiento de diversas modalidades de turismo shamánico han incrementado sus fuentes de ingresos. Gracias a las mejores condiciones de salud, las tasas de mortalidad materno-infantil han disminuido, mientras que las tasas de fecundidad se han mantenido altas, haciendo que los pueblos indígenas amazónicos se encuentren entre los sectores poblacionales con más altas tasas de crecimiento de Latinoamérica (Renshaw y Wray, 2004). Finalmente, la generalización de la educación formal ha resultado en un crecimiento espectacular de las tasas de alfabetismo.

Todo esto, sin embargo, se ha visto contrarrestado por los efectos negativos del proceso de globalización y la expansión del modelo capitalista neoliberal. Así, 
si bien se han titulado millones de hectáreas de territorios indígenas, los países amazónicos han entregado en concesión una superficie mucho mayor a empresas petroleras, gaseras y mineras; concesiones que muchas veces se superponen y afectan a los territorios indígenas. En el Perú, por ejemplo, para el año 2007 se habían titulado poco más de 10 millones de hectáreas de tierras indígenas (Chirif y García Hierro, 2007, p. 176), pero para esa misma fecha se habían entregado en concesión casi 37 millones de hectáreas a compañías extractivas (Surrallés, 2009 , p. 35). De igual manera, si bien los pueblos indígenas amazónicos han podido recuperarse de la catástrofe demográfica producto de la primera y segunda olas de cambio, ahora, como consecuencia de la creciente interacción a nivel nacional e internacional, se han visto particularmente expuestos a enfermedades de transmisión sexual, tales como el VIH/sida, la sífilis y la hepatitis viral B, encontrándose en la actualidad entre las poblaciones de mayor riesgo (Ponce et al., 2017). Finalmente, mientras que las mayores tasas de alfabetismo han contribuido a aminorar o erradicar las formas más crasas de explotación, la calidad de la educación de las escuelas indígenas es tan baja que hace difícil que los jóvenes indígenas puedan acceder a las diversas modalidades de educación superior.

En esta ponencia magistral, presentada en setiembre de 2019 con motivo de los cincuenta años del curso de Antropología Amazónica en la Facultad de Ciencias Sociales de la Pontifica Universidad Católica del Perú, propongo que, a partir de la década de 2010, los pueblos indígenas amazónicos se han visto enfrentados a una nueva ola de cambio, esta vez vinculada con lo que el economista Klaus Schwab (2016) ha denominado la «cuarta revolución industrial». Según Schwab, la primera revolución industrial comenzó alrededor de 1760 con la invención de la máquina a vapor y el uso intensivo de carbón, lo cual permitió mecanizar la producción. La segunda revolución industrial tuvo sus inicios en 1900 con la invención del motor de combustión interna y el uso de petróleo y electricidad, lo cual permitió una rápida industrialización y el desarrollo de la fabricación en serie y a gran escala. La tercera revolución industrial comenzó alrededor de 1960 y se caracterizó por el desarrollo de las computadoras y las tecnologías digitales de información, lo cual, junto con nuevas fuentes de energía, tales como el gas y la energía nuclear, permitieron automatizar la producción.

Según Schwab (2016, p. 7) y otros expertos (Xu et al., 2018), si bien esta nueva revolución industrial tiene sus raíces en las tecnologías digitales que dieron lugar a la tercera revolución industrial, que se distingue de esta última por basarse en una fusión de tecnologías que «está borrando las fronteras entre las esferas de lo físico, lo digital y lo biológico». También difiere en términos de velocidad, 
alcance e impacto. En efecto, la cuarta revolución industrial se caracterizaría por la rapidez de los nuevos descubrimientos, la cual no tiene paralelo en la historia de la humanidad - , pero también por el hecho de que ha involucrado a casi todos los países del mundo y está modificando de una manera mucho más radical los sistemas de producción, gerencia y gobernanza. Según Schwab (2016, p. 7), las posibilidades que ofrecen los nuevos descubrimientos tecnológicos en campos tales como la inteligencia artificial, la robótica, la internet de las cosas, los vehículos autónomos, la impresión en 3-D, la nanotecnología, la ingeniería genética, la ciencia de los materiales, el almacenamiento de energía, la conexión 5G y la informática cuántica son ilimitadas.

No todo, sin embargo, es color de rosa. Schwab (2016, p. 16) es consciente de que, así como estos cambios pueden mejorar significativamente la calidad de vida de la humanidad, también pueden marginar a amplios sectores de la población, incrementando la desigualdad económica y creando, de esta manera, las condiciones para una intensificación de los conflictos sociales. Más aún, el optimismo de quienes ven en la cuarta revolución industrial la solución de muchos de los problemas de la humanidad se ve contrarrestado por el pesimismo de quienes opinan que el sistema capitalista neoliberal ha llegado a sus límites y que el mundo se encuentra al borde de un quiebre total presagiado por la crisis económica, la corrupción corporativa, el crecimiento de la desigualdad, la expansión de los populismos, la guerra comercial entre las grandes potencias, la contaminación del planeta, la extinción masiva de especies y el cambio climático antrópico.

El objetivo de esta charla no es, sin embargo, discutir las ventajas y desventajas de esta nueva revolución industrial, sino explorar cuáles son las nuevas direcciones que podría tomar la antropología amazónica a la luz de esta nueva ola de cambio. Antes de proseguir, debo hacer, sin embargo, algunas aclaraciones. En primer lugar, si bien tengo claro que la antropología amazónica no se limita al estudio y acompañamiento de los pueblos indígenas amazónicos, para los efectos de esta charla me enfocaré en este sector cuya situación es la que más conozco. En segundo lugar, cabe aclarar que cuando me refiero a la Amazonía estoy pensando en la «gran Amazonía», la cual incluye a la Orinoquía y otras áreas de bosque tropical fuera de la cuenca amazónica stricto sensu. En tercer lugar, vale señalar que, si bien hay muchas maneras de hacer antropología amazónica —ninguna de las cuales es excluyente-, en esta charla me refiero fundamentalmente a la antropología académica. Finalmente, debe quedar claro que esta nueva ola de cambio no va a hacer que las situaciones y problemas generados por la anterior ola desaparezcan. Por el contrario, es posible que los profundice aún más. Así, 
ciertos temas - como la lucha de los pueblos indígenas por sus derechos, los problemas generados por la expansión de los frentes extractivistas, la indiferencia estatal frente a la situación de estos pueblos y los debates en torno a la autodeterminación de los pueblos indígenas - continuarán ocupando un lugar importante en la agenda de la antropología amazónica. Lo que propongo es explorar algunas líneas de investigación que, creo, van a adquirir una importancia cada vez mayor de cara a los cambios propulsados por la cuarta revolución industrial. En algunos casos, son temas que han comenzado a ser tratados hace algún tiempo, pero siempre se trata de temas que han sido poco explorados, que van a cobrar una mayor actualidad y en los que vale la pena profundizar.

\section{LAS NUEVAS TECNOLOGÍAS DIGITALES}

Uno de los primeros autores en llamar la atención sobre el impacto de las nuevas tecnologías de información y comunicación fue Steven Cisler, quien en el año 2000 editó un número especial de la revista Quarterly Magazine, publicada por Cultural Survival, con el fin de examinar las reacciones de los pueblos indígenas en general ante la expansión de la internet. Por entonces, el mundo aún estaba experimentando los primeros grandes cambios de la revolución digital y los autores de los diversos artículos incluidos en dicho número hacían notar que, mientras que algunos pueblos indígenas habían adoptado la internet entusiastamente, otros se mostraban renuentes a hacerlo, temerosos de que el acceso ilimitado a la cultura global terminase por avasallar las culturas propias. Para la antropología amazónica — por entonces deslumbrada con las posibilidades que había abierto la noción de perspectivismo multinatural desarrollada por Eduardo Viveiros de Castro (1998) - esta temática pasó desapercibida. Y aunque algunos antropólogos amazonistas, como Oscar Espinosa (1998, p. 98) o Beth Conklin (2002, p. 1051), mencionaban cómo la adopción de la internet y el email estaban cambiando las modalidades de activismo político entre los pueblos indígenas, hubo muy pocos trabajos abocados exclusivamente a investigar este tema.

Es recién a mediados de la década de 2010 cuando surgen los primeros trabajos acerca del impacto de las nuevas tecnologías de información y comunicación entre los pueblos indígenas amazónicos. Estos trabajos ya no tratan sobre los cambios derivados del uso de computadoras y la internet, sino sobre el impacto de los nuevos medios de comunicación social. Así, por ejemplo, Flávia Leite (2014) ha explorado la importancia del uso de Twitter, Facebook y YouTube en la lucha de los indígenas brasileños contra la construcción de megarrepresas en 
sus territorios. Según esta autora, estos medios han permitido a los indígenas amazónicos producir «textos, imágenes y videos digitales que cuestionan las narrativas excesivamente rosas del gobierno sobre los méritos de construir represas en la Amazonía» (Leite, 2014, p. 123). Otros autores han anotado la importancia de las nuevas tecnologías, tales como Google Earth y la plataforma GPS, en el monitoreo, protección y manejo de los territorios indígenas (Plotkin, 2009), la creciente importancia de las plataformas web para los proyectos de revitalización de las lenguas indígenas (Rojas, 2016), o el rol clave que juegan los celulares y los mensajes de texto para conectar a los líderes indígenas con los shamanes que los asesoran al negociar proyectos con el gobierno u otras organizaciones (Micarelli, 2015, p. 171).

Muchos de estos primeros trabajos son descriptivos y con un enfoque mayormente sociológico. Es recién con el artículo de Pirjo Virtanen (2015), sobre cómo los medios de comunicación social promueven, motivan y regulan las relaciones sociales entre los indígenas arahuaco y panohablantes del estado de Acre, Brasil, que se explora este tema desde una perspectiva más antropológica. Tras un seguimiento de seis años a usuarios indígenas de Facebook, Virtanen concluye que las redes sociales no solo están generando nuevas reflexiones sobre el conocimiento y las tradiciones indígenas amazónicas, sino que están cambiando la forma en que los indígenas amazónicos se relacionan con la sociedad nacional. En efecto, según esta autora, a través del uso de Facebook, los indígenas de Acre «han adquirido un nuevo y poderoso instrumento de autorrepresentación y resistencia que les permite afirmar su propia identidad y autonomía étnica» (Virtanen, 2015, p. 357).

Conforme los pueblos indígenas vayan incorporándose cada vez más a la llamada «sociedad de la información» gracias a un mayor acceso a computadoras, laptops, celulares y conexiones rápidas de internet, las nuevas tecnologías de información y comunicación van a jugar un papel aún más importante en todas sus prácticas sociales. Es claro que recién estamos comprendiendo el alcance y la profundidad de los cambios ocasionados por estas nuevas tecnologías. Faltan estudios que exploren cómo estas tecnologías están alterando la socialidad, la convivialidad y los liderazgos indígenas, qué papel juegan en sus luchas económicas y políticas, como están modificando sus actividades educativas y culturales y cómo se han convertido en importantes herramientas para explorar el mundo de los Otros blancos, así como para generar imágenes y representaciones del mundo propio. En breve, queda mucho por hacer. 


\section{URBANIZACIÓN E INDÍGENAS URBANOS}

Ya desde fines de la década de 1990, algunos estudiosos hacían notar que muchos indígenas amazónicos estaban migrando a las ciudades de manera más o menos permanente (González, 1997). Sin embargo, habría de pasar más de un lustro antes de que aparecieran los primeros trabajos etnográficos sobre el proceso de urbanización de los pueblos indígenas amazónicos o los indígenas urbanos. De entre estos caben destacar los trabajos de Roberto Jaramillo (2003) sobre la reconfiguración de las identidades étnicas de los migrantes indígenas en la ciudad de Manaos, el de Cristiane Lasmar (2005) sobre las estrategias matrimoniales de las mujeres tukano y tariana asentadas en la ciudad de São Gabriel de Cachoeira, y el de Daniela Peluso y Miguel Alexiades (2005) sobre el influjo que han tenido las organizaciones medioambientales en los procesos de urbanización y etnogénesis urbana de los Ese Eja.

Por entonces ya estaba claro que el proceso de urbanización de los pueblos indígenas amazónicos no era un fenómeno aislado y estaba adquiriendo un carácter panamazónico. Según datos censales, en el año 2000 poco más de la mitad de los indígenas amazónicos brasileños vivía en centros urbanos (Virtanen, 2010, p. 155). En vista de esto, en su libro Marcando territorio, Alberto Chirif y Pedro García (2007) señalaban que, en contraste con la importancia central que la lucha por la tierra había tenido en el movimiento indígena desde la década de 1960, se habían comenzado a dar importantes procesos de «desterritorialización» mediante los cuales muchos indígenas estaban abandonando sus tierras de origen para irse a vivir a la ciudad. A la vez, hacían notar la necesidad de que las organizaciones indígenas regionales y nacionales incorporaran en sus agendas el tema de los indígenas urbanos, quienes «no dependen del territorio ni enfrentan los mismos problemas que sus paisanos que han quedado en los ríos» (Chirif y García Hierro, 2007, p. 311). Por su parte, los geógrafos Kendra McSweeney y Brad Jokisch (2007) señalaban que los procesos de urbanización no debían ser vistos como opuestos a las luchas indígenas por la tierra o a la preservación de las identidades indígenas. Por lo contrario, a través de la acción política de los indígenas urbanos en coordinación con los líderes locales y regionales, dichos procesos presentarían una oportunidad única para promover objetivos colectivos tales como la lucha territorial, el desarrollo autónomo y el fortalecimiento identitario.

El interés por el fenómeno de los indígenas urbanos crece recién a partir de la década de 2010. En el Perú, uno de los primeros en explorar este tema ha sido Oscar Espinosa. Sobre la base de un estudio preliminar de cuatro casos, Espinosa 
(2009, p. 52) planteaba que no todos los pueblos indígenas de la Amazonía se relacionan con lo urbano de la misma manera. Mientras que algunos migrantes urbanos invisibilizan su identidad indígena, otros la reafirman a través de la acción organizativa, y otros más, en lugar de migrar a las ciudades, tienden a urbanizar sus comunidades. En años posteriores se han publicado varios trabajos que analizan desde las causas de los crecientes procesos de urbanización (Arcila, 2011) hasta la participación de los indígenas amazónicos en la construcción de territorialidades urbanas (Peña Márquez, 2011), o la «hipermarginalización» de la que son objeto los indígenas amazónicos cuando migran a la ciudad (Bessire, 2014).

En el Perú cabe destacar la obra de Ismael Vega Díaz (2015) sobre las estrategias de inserción social de los indígenas amazónicos en la ciudad de Lima, las cuales incluyen la preservación y reinvención de sus identidades étnicas, la recreación de sus costumbres culturales y el mantenimiento de relaciones permanentes con sus comunidades de origen mediante el uso de diversos medios de comunicación, y en especial, de las nuevas tecnologías digitales. Esta compleja interrelación entre los indígenas urbanos y sus paisanos de las comunidades es también uno de los principales ejes de investigación del conjunto de artículos publicados por Daniela Peluso (2015) en el Journal of Latin American and Caribbean Anthropology. Más recientemente, Fernando Santos Granero y Emanuele Fabiano (2019) organizaron un simposio sobre «Imaginarios urbanos en la Amazonía indígena», con el objeto de explorar el papel que juegan estos imaginarios, en tanto referentes de poder y alteridad, como facilitadores de $-\mathrm{O}$ frenos a- los procesos de migración urbana.

Todos estos autores anotan que los procesos de urbanización ponen sobre el tapete la cuestión de la supervivencia y continuidad de los pueblos indígenas amazónicos, pero mientras que algunos piensan que estos procesos socavan las identidades indígenas y generan una mayor aculturación (Mayor y Bodmer, 2009 , p. 64), otros afirman que los indígenas urbanos no están necesariamente condenados a dejar de ser indígenas, ya que ser indígena es una «forma de ser» y no una «forma de estar» (Santos Granero, 2007, p. 16), y hacen un llamado para que se reconozca «a los indígenas urbanos como indígenas con los mismos derechos que sus paisanos que viven en las comunidades rurales» (Espinosa, 2009 , p. 57). De hecho, algunos indígenas amazónicos afirman que la ciudad los ha vuelto más indígenas y se ven a sí mismos construyendo una «ciudad de paisanos» al interior de la ciudad blanca (Sánchez, 2010, pp. 146, 150).

Estos trabajos han tocado algunos de los muchos temas que plantea el proceso de urbanización por el que atraviesan los pueblos indígenas amazónicos, 
pero aún queda mucho por estudiar. ¿Cómo afectan estos procesos las redes de parentesco, las prácticas culturales, las cosmovisiones o la praxis política tanto de los migrantes urbanos como de aquellos que se quedan en las comunidades? ¿Cuáles son las bases de las nuevas y reconfiguradas identidades étnicas urbanas y cómo se expresan en estos nuevos contextos? ¿Cómo se conectan el proceso de migración urbana con su opuesto, el proceso de «ruralización», entendido aquí como la migración indígena hacia áreas más remotas para escapar de los aspectos más disruptivos de la dinámica urbanizante de la sociedad nacional? Finalmente, ¿se puede afirmar que, así como en algunas áreas existe un proceso de urbanización de las comunidades rurales, también existe un proceso de «indigenización» de los espacios urbanos?

\section{INTELECTUALES Y ARTISTAS INDÍGENAS}

El fenómeno de los intelectuales y artistas indígenas amazónicos es reciente y está íntimamente ligado a los procesos de urbanización. En efecto, estos surgen mayormente de entre los jóvenes que han migrado o nacido en la ciudad y que tienen cierto grado de educación superior (Espinosa, 2007). Los primeros trabajos sobre la nueva intelectualidad indígena se remontan a inicios de este siglo (Bartolomé, 2002), pero no es sino hasta la década de 2010 que el tema comienza a atraer la atención de los científicos sociales (Fernández, 2010; Flores Carlos, 2011; Canales Tapia y Rea Campos, 2013). Sin embargo, la mayor parte de estos trabajos tempranos hace referencia a los intelectuales indígenas andinos y solo menciona de paso a los intelectuales indígenas amazónicos. Recién en los últimos años ha habido un tímido intento por entender los procesos de forja de estos nuevos intelectuales y el papel que juegan en los movimientos indígenas amazónicos.

Autores como Norma Meneses (2013) y Pedro Canales (2014) reconocen la existencia de dos tipos de intelectuales indígenas: los intelectuales tradicionales, fundamentalmente ancianos sabedores, shamanes y sacerdotes que actúan como custodios de los conocimientos tradicionales de sus pueblos, y los intelectuales modernos, o «etnointelectuales», educados en contextos urbanos y con cierto nivel de formación académica. De acuerdo con Meneses (2013, p. 93), en el caso de la Amazonía peruana «es la intelectualidad tradicional la que lidera el accionar de sus pueblos en defensa de su cultura y su territorio», en la medida en que la intelectualidad urbana aún consiste en «un número pequeño de profesionales, donde priman los profesores de Educación Bilingüe, y algunos alumnos universitarios». 
Esto está claramente cambiando a lo largo y ancho de la Amazonía y desde hace unos años los intelectuales indígenas urbanos han comenzado a jugar un papel más importante debido a su activa participación en los movimientos indígenas (Pataxó, 2017). De hecho, muchos autores consideran la distinción entre intelectuales y dirigentes indígenas como una distinción espuria, producto de una visión eurocéntrica, y proponen que ambos roles representan trayectorias interculturales interdependientes (Monroy-Álvarez, 2008; Ortiz Rodríguez, 2015). La obra Entre la dependencia y la libertad: siempre awajún, escrita por el intelectual y dirigente awajún Gil Inoach Shawit, es una clara expresión de lo fructífera que puede ser esta conjunción. Hay menos consenso en cuanto al papel que juega la intelligentsia indígena. Algunos, como Miguel Bartolomé (2002, p. 158) saludan el hecho de que estos nuevos intelectuales son «portadores de lenguajes e ideas innovadoras», pero señalan que, con frecuencia, estos entran en conflicto con las perspectivas de las comunidades en la medida que han adquirido su papel de mediadores interculturales «por su capacidad de manejar la lengua y los códigos de sus interlocutores, más que por su participación en las lógicas y tradiciones de su propia cultura». Otros, en cambio, afirman que, a pesar de estas contradicciones, los intelectuales urbanos están cumpliendo «un rol fundamental en la revitalización cultural y lingüística de sus pueblos, además de sus tareas más urgentes como la defensa de su territorio y sus derechos humanos y ciudadanos» (Meneses Tutaya, 2013, p. 85; ver también Wroblewski, 2014).

Al igual que los intelectuales, muchos de los artistas indígenas amazóni$\cos$ - mayormente pintores y escultores - son migrantes que se han formado o adquirido renombre en contextos urbanos. Si bien los primeros trabajos sobre este tipo de artistas ya aparecen a fines de la década de 1990 o comienzos del nuevo siglo (Soria, 1998, 2001; Landolt, 2000; Macera, 2001; Soria y Casanto, 2002), recién a fines de la década de 2000 comienzan a publicarse los primeros trabajos de corte antropológico. El Perú destaca como uno de los países que ha concedido mayor importancia a este tema. Una de las pioneras en este campo ha sido Luisa Elvira Belaunde (2008, 2010, 2011, 2016), quien ha trabajado de cerca con pintores huitoto, asháninka y shipibo-conibo. A través de sus trabajos, basados en largas entrevistas con dichos pintores, Belaunde busca no solo revelar las conexiones entre sus pinturas y las mitologías o los imaginarios shamánicos de las que se nutren, sino transmitir las reflexiones de los propios artistas sobre su arte, su historia y su identidad.

Esta línea de investigación, que busca entender el fenómeno de los artistas plásticos indígenas a partir del análisis del contenido y simbolismo de sus obras, 
ha sido seguida por otros autores con gran éxito dentro y fuera del Perú. Mientras que algunos trabajos continúan teniendo por foco a artistas individuales (Castillo, 2015), otros se enfocan en diversos colectivos, tal como sucede con la tesis de maestría de Daniel Castillo (2013) sobre los pintores shipibo de Cantagallo, en Lima; la tesis doctoral de Liliana Cortés (2015) sobre la pintura amazónica en las ciudades de Iquitos, Pucallpa, Pebas y Paucarquillo, o el trabajo de Hugo Tangarife y otros (2018) sobre los «pintores visionarios» amazónicos. En otros casos el foco está puesto en el análisis de una exhibición, tal como el trabajo de Beatriz Matos y Luisa Elvira Belaunde (2014) sobre la exposición ¡Mira! Artes visuales contemporáneas de los pueblos indígenas, o en las actividades de un movimiento artístico como MAKHU, el Movimiento dos Artistas Huni Kuin del estado de Acre, como es el caso del trabajo de Amilton Pelegrino (2015).

En otra línea de investigación, algunos autores, como María Eugenia Yllia (2009, 2011) o Giuliana Borea (2010), se preguntan si la eclosión y éxito de los plásticos indígenas es resultado de su lucha por conquistar nuevos espacios y géneros pictóricos o si responde a las modas y demandas del mercado de arte contemporáneo. Más que el contenido simbólico de las pinturas, lo que les interesa a estas autoras es analizar la praxis artística como proceso social. En ambos casos, concluyen que este fenómeno surge a raíz de la confluencia de una serie de factores entre los que destacan el afán de los artistas por superar lo artesanal de modo de lograr espacios de exhibición y validación de su arte por la cultura oficial, la valorización de lo amazónico gracias a los estudios antropológicos, el multiculturalismo y la crítica poscolonial, y el surgimiento de una nueva generación de curadores y promotores dentro del circuito del arte que ha permitido el surgimiento de nuevos valores artísticos.

Aun cuando estos trabajos han tocado algunos de los posibles temas de investigación sobre los intelectuales y artistas plásticos amazónicos, queda aún mucho campo por desbrozar. ¿En qué medida sus discursos y obras siguen siendo fieles a las filosofías y visiones del mundo de sus pueblos? ¿Cuál es el impacto de sus producciones en las formas de autorrepresentación, la conciencia histórica y las prácticas culturales de sus pueblos? ¿Cómo confrontan, esquivan o incorporan las contradicciones que les plantea su condición de mediadores interculturales? Estas preguntas cobrarán una importancia cada vez mayor conforme se profundicen los procesos de urbanización y la distinción entre indígenas urbanos y rurales. 


\section{LA JUVENTUD MILENIAL Y POSMILENIAL}

Como se ha visto, los intelectuales y artistas plásticos indígenas provienen del sector de jóvenes que ha migrado o nacido en la ciudad. ¿Pero qué pasa con los otros jóvenes indígenas, mileniales o posmileniales, aquellos que han migrado a la ciudad y no han logrado su sueño de profesionalizarse o aquellos que han optado por quedarse en sus comunidades? De acuerdo con las definiciones más aceptadas, los mileniales o Generación Y son aquellos nacidos entre 1981 y 1996, mientras que los posmileniales o Generación Z son los que nacieron entre 1997 y el presente. Los primeros son la generación de la internet: han crecido rodeados de aparatos electrónicos, conectados en línea y crecientemente involucrados en redes globales. Los segundos son la generación de los llamados «nativos digitales»; los que crecieron manejando smartphones y tablets, participan activamente en las redes sociales y están acostumbrados a estar permanentemente comunicados. ¿Cuáles son los problemas y aspiraciones de los jóvenes indígenas de estas generaciones? ¿Y en qué se parecen o diferencian de los jóvenes mileniales y posmileniales globales? Esta pregunta cobra particular importancia en la medida en que, si nos basamos en el caso de Brasil, para el año 2010 los jóvenes indígenas amazónicos de 0 a 24 años representaban más de la mitad de la población indígena total: $56 \%$ frente al $42 \%$ de ese mismo grupo etario en el país (IBGE, 2010).

Hay muy pocos trabajos sobre los jóvenes indígenas amazónicos, ya sea urbanos o rurales, y la mayor parte de estos ha sido escrita durante la última década. Quien más ha trabajado esta temática es Pirjo Virtanen (2006, 2009a, 2009b, 2010, 2012, 2015), quien ha publicado varios artículos y un libro sobre los jóvenes indígenas apurinã, cashinahua y manchineri que viven en la ciudad de Rio Branco, capital del estado de Acre. En su primer artículo sobre este tema, Virtanen (2006, p. 162) planteaba que los jóvenes manchineri urbanos difieren significativamente de sus pares rurales en términos de su estilo de vida, nutrición, conocimiento tradicional y uso del lenguaje. La mayoría de los manchineri urbanos han nacido en la ciudad y tienen pocos recuerdos de su vida en la comunidad. Su mayor preocupación es la educación, el empleo, la discriminación y la falta de recursos económicos. Lamentan su pobre conocimiento de la lengua y las tradiciones manchineri. Sin embargo, muchos de estos jóvenes participan en ceremonias de ayahuasca para «aprender» y «poder tomar decisiones» y algunos han aprendido las canciones shamánicas típicas de estos rituales y ocupan posiciones importantes en dichas ceremonias. Virtanen (2006, p. 164) concluye que, a través de su participación en estas ceremonias y en encuentros culturales y 
políticos, los jóvenes manchineri están reconstruyendo sus tradiciones culturales a la par que incrementando su capital social o simbólico para poder interactuar en mejores términos con los diversos actores de la sociedad dominante. Una situación similar se da entre los jóvenes waorani que deciden quedarse en sus comunidades, quienes recurren al pasado guerrero de sus ancestros y a la imaginería de las películas de acción de Sylvester Stallone, Jean Claude Van Damme o Bruce Lee para construirse una nueva identidad que se nutre a la vez de lo tradicional y lo moderno, sin llegar a ser ni la una ni la otra (High, 2015, capítulo 3).

La tensión entre tradición y modernidad, comunidad y ciudad, viejos y jóvenes, asimilación o resistencia identitaria y las diversas estrategias que los jóvenes indígenas desarrollan para poder lidiar con la misma es una constante de los trabajos sobre la juventud indígena amazónica. Sin embargo, los pocos autores que han explorado el tema encuentran que dicha tensión no siempre se resuelve o decanta, como se podría esperar, por el lado de la modernidad. Virtanen (2009a, p. 111), por ejemplo, plantea que muchos jóvenes indígenas urbanos asumen las pautas de comportamiento de las culturas juveniles globales como un modo de indicar que son miembros de la sociedad dominante y, por lo tanto, conocen sus códigos y costumbres. Pero, a la vez, afirma que la adopción de estas pautas no necesariamente socava su identidad indígena o el significado de las tradiciones culturales propias, ya que «para los jóvenes indígenas sus tradiciones culturales están conectadas a ciertos tiempos, lugares y personas que les ofrecen un tipo de fortaleza que otros jóvenes no poseen» (Virtanen, 2009a, p. 107).

Oscar Espinosa (2012) llega a una conclusión semejante en su estudio sobre los jóvenes shipibo en las ciudades de Lima, Pucallpa y Yarinacocha. Plantea que el problema no consiste en «ser o dejar de ser shipibo», sino en qué significa ser shipibo en los nuevos contextos sociales y culturales en los que estos se encuentran insertos. Afirma que hay múltiples maneras de ser shipibo y que, a pesar de los temores de los más viejos sobre cómo los jóvenes están olvidando las tradiciones de su pueblo, existe evidencia de que, a través de sus organizaciones juveniles, los jóvenes shipibos urbanos continúan absorbiendo y trasmitiendo los valores morales tradicionales, que son considerados indispensables para la constitución de una «buena persona», es decir, una persona fuerte, sabia y reflexiva. Son estos valores morales los que les proporcionan un sentido de continuidad con sus padres y abuelos.

Resulta claro de estos pocos estudios, que los indígenas mileniales y posmileniales tienen una visión diferente de lo que significa ser indígena y que se encuentran en una coyuntura de cambio y experimentación (Ortiz, 2015; 
Pacheco de Oliveira, 2017). Esto es así no solo para los jóvenes urbanos sino también para aquellos que viven en comunidades indígenas altamente urbanizadas (Wei, 2017). Pero también es claro que no todos los jóvenes indígenas que comparten rasgos con los mileniales y posmileniales globales quieren dejar —o están condenados a dejar - de ser indígenas. Como dice Jaime Calapucha, un joven quichua amazónico del Ecuador: «Puedes tener una casa moderna y una computadora, pero necesitas conservar tu cultura» (Wei, 2017). De hecho, de acuerdo con algunos autores, muchos de estos jóvenes - tales como los machiguenga de La Convención - parecen estar utilizando su experiencia como migrantes urbanos, su educación superior y sus modernas identidades indígenas para promover la resiliencia de sus comunidades (Steele, 2018). Esta línea de investigación apenas está comenzando a ser explorada. Quedan por analizar las diversas estrategias desarrolladas por los jóvenes indígenas mileniales y posmileniales para negociar las nuevas situaciones sociales, culturales y políticas a las que se ven enfrentados, así como cuáles son sus ideas acerca de lo que significa ser indígena en el siglo XXI. También queda por analizar qué pasa con aquellos que cortan los lazos con sus comunidades de origen, niegan su identidad y procuran «pasar» por mestizos. ¿Es esta ruptura absoluta e irreversible o se presta para cambios de rumbo de acuerdo con las vicisitudes de las circunstancias personales o sociales de los individuos involucrados?

\section{REVITALIZACIÓN CULTURAL Y PATRIMONIO}

Los temas de revitalización cultural y patrimonialización están íntimamente conectados, en la medida en que el primer fenómeno crea las condiciones para el surgimiento de proyectos de patrimonialización de la herencia cultural. En una coyuntura en que gran número de indígenas amazónicos migra a las ciudades, en que los jóvenes indígenas amazónicos parecen estar distanciándose de sus raíces culturales y en que las generaciones mayores temen por la supervivencia cultural de sus pueblos, estos dos fenómenos parecen ser contraintuitivos. Y, sin embargo, una serie de trabajos que comienzan a publicarse desde fines de la década de 2000 demuestran que, ante el avasallamiento de las sociedades dominantes y el debilitamiento de las tradiciones e identidad cultural, muchos pueblos indígenas han comenzado a imaginar, diseñar e implementar proyectos para preservar o recuperar su acervo cultural. 
Esto es particularmente cierto en el campo lingüístico, donde el impacto de los procesos aculturativos es más notorio. Y es en este campo en el que se encuentra la mayor parte de los trabajos sobre revitalización cultural. Algunos de estos trabajos analizan los desafíos que deben enfrentar aquellos pueblos que han perdido su lengua parcial o completamente y que, por diversas razones, se proponen recuperarla. El trabajo de Pilar Valenzuela (2010) sobre los shiwilu o jeberos del Perú; la tesis de Sarah Shulist (2013) sobre los diversos grupos indígenas que habitan la ciudad de São Gabriel de Cachoeira, y el trabajo de Sidney Facundes et al. (2018) sobre los apurinã del estado de Amazonas, en Brasil, se inscriben dentro de esta línea de investigación, procurando identificar las causas que llevan a la pérdida de las lenguas indígenas y las posibles estrategias que se podrían poner en marcha para recuperarlas. En esta línea de investigación destacan los trabajos de Shulist $(2015,2016)$, los cuales recalcan la naturaleza politizada de los procesos de revitalización lingüística, el rol clave que en estos procesos juega la noción de «autenticidad», el papel del Estado y de quienes apoyan a los pueblos indígenas en el moldeamiento de la «indigeneidad», y cómo estos procesos plantean cuestiones políticas más amplias, tales como qué significa ser indígena o no indígena. Otros importantes trabajos en este campo examinan experiencias concretas de revitalización lingüística, tales como los de Esteban Monsonyi y Jorge Pocaterra (2004) sobre los Kariña, Baré, Baniwa y Warekena de Venezuela; Isabel Romero (2015) y Juan Alvaro Echeverri et al. (2016) sobre los nonuya de Colombia; Jorge Gómez (2008) sobre los sia pedee de Ecuador; Karen Rojas (2016) sobre los kukama-kukamiria del Perú, o Pedro Plaza (2012) sobre los yuracaré de Bolivia.

Si bien los procesos de revitalización lingüística son los que más atención han recibido por parte de lingüistas y antropólogos, estos no son los únicos trabajos sobre revitalización cultural en la Amazonía indígena. Uno de los temas que ha recibido particular atención es el de los «neoshamanismos» y la recreación de ceremonias shamánicas como la de la ayahuasca. Liliam Barros y Robin Wright (2015), por ejemplo, analizan la revitalización de las malocas tradicionales entre los Desana y Baniwa de la Amazonía noroccidental como espacios para la celebración de ceremonias curativas. A partir del análisis de los casos de Colombia y Brasil, Jean Langdon $(2013,2016)$ propone que el shamanismo amazónico ya no puede ser visto como una filosofía o lógica aislada, sino como una práctica dialógica que emerge y se va modificando a partir de las expectativas de los varios actores involucrados, sean estos indígenas o no. Los autores de los trabajos publicados por Beatriz Caiuby y Clancy Cavnar (2014, p. 4) en el volumen Ayahuasca 
Shamanism in the Amazon and Beyond, asumen una posición similar, proponiendo que los indígenas y mestizos amazónicos desplazados están «involucrados en la creación sincrética de rituales shamánicos que les permite construir alianzas étnicas y estrategias políticas para sobreponerse a sus posiciones marginales». De esta manera, la «reinvención de la autenticidad» se convierte en un instrumento tanto para la revitalización de las tradiciones indígenas como para la emergencia de nuevas identidades étnicas.

Con frecuencia, las experiencias de revitalización cultural están asociadas a proyectos de patrimonialización, ya sea de bienes culturales tangibles (por ejemplo, ceremonias, objetos rituales o sitios sagrados) o intangibles (por ejemplo, canciones, mitos, conocimientos curativos). El interés por el tema de los derechos de propiedad cultural y el patrimonio indígena viene desde fines de la década de 1990 (Simpson, 1997; Brown, 1998, 2003), pero no es sino tras la adopción de la Convención para la Salvaguardia del Patrimonio Cultural Inmaterial por la Unesco en 2003 cuando los estudios sobre patrimonialización de las culturas indígenas cobran fuerza. Aquí, nuevamente, las prácticas shamánicas ocupan un lugar central (Caicedo, 2010; Loures y Alves, 2017; Capredon, 2018). Pero también hay una diversidad de trabajos que analizan los procesos de patrimonialización de los mitos y conjuros trumaí (Vienne y Allard, 2005), de los cantos shamánicos chacobo (Erikson, 2011), de los diseños geométricos shipibo-conibo (Belaunde, 2012), de los rituales karajá y suruí (Nahum Claudel et al., 2017), o de las flautas y timbales mosetenes (Barrientos, 2017).

Para muchos autores, estos procesos, que de una u otra manera han afectado a la mayor parte de los pueblos indígenas amazónicos, pueden contribuir a poner freno e incluso revertir los embates aculturativos de las sociedades nacionales, constituyéndose en importantes instrumentos para la supervivencia y continuidad de las culturas y sociedades indígenas (Simpson, 1997). Otros autores son más escépticos, ya sea criticando el esencialismo de la noción de patrimonio cultural (Chaumeil, 2009; Barrientos et al., 2017), o advirtiendo sobre los excesos de los esfuerzos de patrimonialización, que pueden resultar en la «fosilización» de las culturas indígenas, tal como propone Alexandre Fernandes (2011), o en su «zombificación», es decir, en la elevación de ciertos elementos de la herencia cultural indígena a la condición de «muertos vivientes», tal como sugiere Santos Granero (2017). Estas posiciones divergentes plantean nuevas interrogantes, las cuales solo podrán ser dilucidadas en los años venideros, conforme estos procesos se vayan consolidando o debilitando. 


\section{PERCEPCIONES DEL CAMBIO}

Si la tercera ola de cambio ha transformando radicalmente a las sociedades indígenas amazónicas, la cuarta ola de cambio las está transformando aún más. Algunos de estos cambios ya están en marcha, pero otros ni siquiera son predecibles. Un tema que ha sido poco explorado, y que seguramente va a reclamar una mayor atención de los antropólogos amazónicos, es el de las percepciones indígenas sobre estos cambios, especialmente aquellos asociados con la expansión de las actividades extractivas, el creciente deterioro ambiental y la rápida pérdida de la identidad y los valores culturales propios. Desde comienzos de siglo se ha escrito una diversidad de trabajos sobre cómo los pueblos indígenas amazónicos perciben empíricamente los cambios causados por, entre otras cosas, la deforestación (Menton, 2003; Fernández-Llamazares et al., 2016), la explotación petrolera (Macdonald, 2010; Okamoto, 2011; Swing et al., 2012), o el cambio climático (Kronik y Verner, 2010; Fernández-Llamazares, 2015; Bold, 2019). Junto con estos, también han aparecido unos pocos trabajos que buscan desentrañar cómo los indígenas amazónicos interpretan estos cambios según sus ontologías y cosmovisiones, ya sean estas propias o adoptadas.

Estos trabajos sugieren que muchos pueblos indígenas perciben estos cambios como signos de que el mundo se aproxima a su fin. El primero de estos ha sido La chute du ciel (The Falling Sky), en el que el antropólogo francés Bruce Albert recoge los pensamientos del shamán yanomami Davi Kopenawa (Kopenawa y Albert, 2010, 2013). Kopenawa narra cómo, desde que en la década de 1980 los garimpeiros - o mineros informales - comenzaron a invadir sus tierras excavando en busca de oro, los pilares de metal que sostienen el cielo han comenzado a debilitarse. Peor aún, los vapores de sus máquinas han producido epidemias que han enfermado al cielo y diezmado a los yanomami. Según Kopenawa, hasta ahora, con la ayuda de los espíritus del bosque, los shamanes yanomami han logrado evitar que el cielo caiga. Pero conforme el cielo se siga debilitando, los yanomami vayan olvidando sus costumbres y ya no queden shamanes para sostener el cielo enfermo, este caerá sepultando a todos los habitantes de la tierra. Entonces, lo único que quedará será esperar a que el dios creador, Omoma, se decida a crear una nueva tierra y una nueva humanidad. En una vena similar, en 2010, Mandu, un shamánjaguar baniwa de Venezuela, advertía que las empresas petroleras habían perforado dos de los tres mundos subterráneos existentes y que el fin del mundo sobrevendría cuando atravesaran el tercer mundo subterráneo, en donde habita el dueño de los espíritus animales (Wright, 2013, p. 141). Al igual que los yanomami y baniwa, 
los urarina del Perú afirman que la tierra está enferma y que lo único que impide que el mundo llegue a su fin es la activa labor de los shamanes (Walker, 2019).

Este tipo de narrativas apocalípticas han sido reportadas en varios pueblos indígenas amazónicos y parecen estar cobrando cada vez mayor fuerza. En esto los indígenas amazónicos no parecen estar solos, tal como se desprende de las conclusiones del último informe del Panel Intergubernamental sobre Cambio Climático de las Naciones Unidas (IPCC, 2019), de la última Advertencia a la Humanidad de los Científicos del Mundo (AWS, 2017), de las numerosas publicaciones sobre los riesgos del cambio climático (Wallace-Wells, 2019; McKibben, 2019), y de la avalancha de películas y novelas que tienen por tema el colapso del mundo tal como lo conocemos. Sin embargo, esta convergencia es solo aparente. Mientras que las narrativas apocalípticas occidentales atribuyen el fin del mundo a guerras de carácter geopolítico, epidemias creadas en laboratorios o la depredación y contaminación del medio ambiente causada por corporaciones avariciosas y patrones de consumo no sostenibles, los pueblos indígenas amazónicos ponen el énfasis en el desorden físico, social y moral causado por las actividades de los blancos. La aparición de la pandemia Covid-19 en diciembre de 2019 en Wuhan, China, apenas tres meses después de haber presentado esta ponencia, ha recrudecido la percepción entre los pueblos indígenas amazónicos de que la tierra está enferma y el fin del mundo se acerca.

En algunos casos, como el de los yanomami, baniwa y urarina, estas narrativas se basan enteramente en ontologías y cosmovisiones propias, pero en otros encuentran sustento en reformulaciones de viejas ideas de acuerdo con las nuevas experiencias históricas o en la adopción e indigenización de ontologías y cosmovisiones foráneas. Ejemplo del primer caso es el trabajo de Fernando Santos Granero y Frederica Barclay (2011) sobre los rumores que comenzaron a circular entre los awajun, wampis y asháninka a fines de 2008 acerca de una serie de seres sobrenaturales con aspecto de blancos que ingresaban a sus comunidades en aparatos voladores o se infiltraban a través de agencias y programas sociales del gobierno con el fin de secuestrar y matar a sus pobladores para una diversidad de fines. Estos rumores surgieron en un contexto en el que, con el apoyo del Estado, numerosas empresas extractivas se encontraban ocupando y explotando vastas porciones de los territorios indígenas. Las historias de estos encuentros se nutren de ecocosmologías amazónicas ampliamente difundidas que entienden que la fuerza vital que anima al mundo es escasa, en constante circulación y desigualmente distribuida, lo que hace que todas las especies - incluyendo los blancos e indígenas - compitan entre sí para acumular la mayor cantidad de fuerza vital posible. En dicha coyuntura, 
los awajun, wampis y asháninka percibían la nueva arremetida capitalista como un intento del Estado en alianza con las empresas extractivas no solo por saquear sus fuerzas de vida, sino por exterminarlos de una vez por todas.

En otros casos, el apocalipticismo indígena se ha nutrido de imágenes y motivos cristianos. A fines de la década de 1990, los participantes del movimiento profético Aleluya entre los kapon del estado de Roraima, Brasil, afirmaban que el fin del mundo estaba próximo (Azevedo de Abreu, 1995, pp. 92-94). Veían las señales de su inminencia en una serie de cambios que estaban afectando a la tierra y su gente: los días eran más cortos, la tierra se estaba agrietando, las inundaciones eran más frecuentes, los bebés estaban naciendo con malformaciones, las enfermedades estaban aumentando, la gente se estaba haciendo vieja más pronto y la vida en las ciudades era cada vez más corrupta y ruin. Sus líderes afirmaban que solo a través de la continua ejecución de sus cantos y rituales los seguidores del movimiento lograrían alcanzar la inmortalidad y evitar que la Tierra fuera destruida. Esto sucedería tras la llegada de un mesías — al que algunos identificaban con Jesucristo, otros con «el hijo del padre» y otros más como el «sabio» o el «banco» o chamán—, quien habría de instaurar un nuevo orden cósmico y moral.

Movimientos similares han surgido entre los kalapalo y kuikuro del Alto Xingú en 2006 (Fausto y Vienne, 2014) y entre los totobiegosode del Chaco paraguayo, un subgrupo ayoreo en aislamiento voluntario contactado en 2004 (Bessire, 2011). Entre estos últimos, los cambios experimentados antes y después del contacto han sido tan radicales que perciben su pasado como algo moralmente indigno que es preciso olvidar. En su lugar han adoptado una «ecología moral radicalmente diferente $[. .$.$] estructurada en torno al futuro retorno de Jesús y a la$ transformación corporal de los creyentes» (Bessire, 2011, p. 749). En efecto, su adhesión a la fe cristiana se basa en la esperanza del fin y renacimiento del actual orden moral y social, el cual culminará en la transformación de los creyentes en seres celestiales, prósperos y de piel blanca (Bessire, 2011, p. 744).

Se trata, al decir de Bessire (2011, p. 744), de respuestas y movimientos en que la continuidad cultural y biológica requiere una ruptura y viceversa. Percepciones y movimientos sumamente creativos de cara a la violencia capitalista, que en algunos casos recurren a la tradición propia y en otros a las foráneas con el fin de crear algo nuevo: un mundo en que se restablezca el orden moral y social roto por las acciones de los intrusos blancos. Hay, sin embargo, muchas interrogantes que quedan por responder. ¿Existen elementos comunes en las diversas formas de apocalipticismo indígena? ¿Qué hace que algunos pueblos indígenas amazónicos sean más proclives a este tipo de percepción que otros? ¿En qué medida estas 
percepciones transforman la socialidad y capacidad de lucha de los pueblos indígenas amazónicos? E igualmente importante: ¿qué efecto están teniendo estas visiones indígenas en las percepciones y discursos de los no indígenas globales? Conforme se profundicen los cambios de esta cuarta ola y se multipliquen este tipo de movimientos, estas preguntas irán cobrando una mayor urgencia.

\section{A MODO DE CONCLUSIÓN}

Es probable que haya otros temas de igual o mayor relevancia que los que he enumerado aquí. Es muy probable, también, que muchos de los temas que han venido tratándose en las últimas décadas —el carácter perspectivista de las ontologías indígenas amazónicas, la dimensión construccional de las nociones de corporalidad, personeidad y subjetividad, el carácter cósmico de la socialidad indígena amazónica y la tensión dinámica entre predación y convivialidad, por mencionar solo algunos - seguirán siendo explorados. Pero es claro que los temas aquí mencionados van a adquirir una mayor prominencia según los cambios impulsados por la cuarta revolución industrial se vayan consolidando.

También parece claro que los cambios de la cuarta ola van a modificar o redefinir la forma de hacer antropología. Hasta ahora los antropólogos amazonistas han podido llevar a cabo sus investigaciones etnográficas de manera semejante a como lo hacían nuestros antecesores del siglo XX, es decir, como un emprendimiento altamente individual, basado en la convivencia prolongada con una colectividad bien definida y el establecimiento de relaciones más o menos jerárquicas con informantes privilegiados, $\mathrm{y}$ amparado en la distancia geográfica respecto de los sujetos de estudio. Pero conforme se profundicen los procesos de urbanización, aumente el número de intelectuales y profesionales indígenas y haya un mayor acceso a la información a través de las nuevas tecnologías digitales, la distancia geográfica y social entre indígenas y antropólogos va a disminuir significativamente.

Esta nueva realidad va a requerir un cambio en el signo de la relación entre antropólogos e indígenas, quienes podrán acceder, leer y evaluar nuestros trabajos a la distancia de un clic del ratón. También va a requerir desarrollar nuevas modalidades de trabajo etnográfico en las que los indígenas amazónicos tengan un mayor protagonismo. Si bien la propuesta de una antropología más participativa, basada en una colaboración más simétrica entre antropólogos y sujetos etnográficos, no es algo nuevo (Lassiter, 2005a, 2005b; Fluehr-Lobban, 2008; Rappaport, 2008), aún son muy pocos los trabajos académicos producidos bajo estas nuevas 
condiciones. En este sentido, tal vez sea hora de que la antropología académica preste más atención a la antropología aplicada o antropología de acción, en las que este tipo de colaboraciones han sido y son mucho más frecuentes.

La cuarta revolución industrial promete cambiar de manera radical la vida de todos los seres humanos. Aún no queda del todo claro la naturaleza, el alcance y la profundidad de los cambios por venir, pero lo que sí resulta evidente es que los pueblos indígenas amazónicos van a tener que confrontar desafíos tan grandes - aunque de diferente naturaleza - como los que debieron enfrentar tras el encuentro colonial. Algunos temen (o confían) en que estos cambios finalmente van a acabar con los pueblos indígenas amazónicos, tal como se viene prediciendo desde hace mucho tiempo. Yo creo personalmente que, basados en su resiliencia y capacidad de adaptación, estos pueblos van no solo a superar los desafíos presentados por esta nueva revolución industrial, sino a resurgir aún más fortalecidos. Les corresponderá a ustedes, las nuevas generaciones de antropólogos amazonistas, acompañarlos en estos procesos.

\section{REFERENCIAS BIBLIOGRÁFICAS}

Arcila, Óscar H. (2011). La Amazonía colombiana urbanizada: un análisis de sus asentamientos urbanos. Bogotá: Instituto Amazónico de Investigaciones Científicas-Sinchi.

Azevedo de Abreu, Stela (1995). Aleluia: o banco de luz. Tesis de maestría, Universidade Estadual de Campinas.

AWS (2017). World Scientists' Warning to Humanity. Alliance of World Scientists. Documento electrónico; consultado julio de 2019. Recuperado de http://www. scientistswarning.org/warning-to-humanity-second-notice/

Barrientos Salinas, J. Alejandro; Silva Arratia, Mariela y Taller, B. (2017). Flautas y timbales: apuntes críticos sobre patrimonio cultural desde la vida social de los instrumentos musicales en la TCO Mosetén. Textos Antropológicos, 18(1), 67-84.

Barros, Líliam y Wright, Robin M. (2015). Music, Ritual and Cosmology of the Desana and Baniwa People of the Upper Rio Negro, Amazon, Brazil: A Collaborative Research. El oído pensante, 3(2). Recuperado de http://ppct.caicyt.gov.ar/index. php/oidopensante

Bartolomé, Miguel Alberto (2002). Movimientos indios en América Latina: los nuevos procesos de construcción nacionalitaria. Desacatos, 10, 148-166.

Belaunde, Luisa Elvira (2008). La narración de la memoria Aymenu (Uitoto) en la pintura de Rember Yahuarcani. Tellus, 8(14), 247-255. 
Belaunde, Luisa Elvira (2010). Las Once Lunas de Rember Yahuarcani. Mundo Amazónico, 1, 333-348.

Belaunde, Luisa Elvira (2011). Visión de espacios en la pintura chamánica del sheripiare asháninka Noé Silva Morales. Mundo Amazónico, 2, 365-377.

Belaunde, Luisa Elvira (2012). Diseños materiales e inmateriales: la patrimonialización del kené shipibo-konibo y de la ayahuasca en el Perú. Mundo Amazónico, 3, 123-146.

Belaunde, Luisa Elvira (2016). Donos e pintores: plantas e figuração na amazônia peruana. Mana, 22(3), 611-640.

Bessire, Lucas (2011). Apocalyptic Futures: The Violent Transformation of Moral Human Life among Ayoreo-speaking People of the Paraguayan Gran Chaco. American Ethnologist, 38(4), 743-757.

Bessire, Lucas (2014). The Rise of Indigenous Hypermarginality: Native Culture as a Neoliberal Politics of Life. Current Anthropology, 55(3), 276-295.

Bold, Rosalyn (ed.) (2019). Indigenous Perceptions of the End of the World: Creating a Cosmopolitics of Change. Palgrave: Macmillan.

Borea, Giuliana (2010). Personal cartographies of a Huitoto mythology: Rember Yahuarcani and the enlarging of the Peruvian contemporary art scene. Revista de Antropología Social dos Alunos do PPGAS-UFSCar, 2(2), 67-87.

Brown, Michael F. (1998). Can Culture be Copyrighted? Current Anthropology, 39(2), $163-222$.

Brown, Michael F. (2003). Who Owns Native Culture? Cambridge: Harvard University Press.

Caicedo Fernández, Alhena (2010). El uso ritual de yajé: patrimonialización y consumo en debate. Revista Colombiana de Antropología, 46(1), 63-86.

Caiuby Labate, Beatriz y Cavnar, Clancy (2014). Ayahuasca Shamanism in the Amazon and Beyond. Oxford: Oxford University Press.

Canales Tapia, Pedro (2014). «Etnointelectualidad»: construcción de «sujetos letrados» en América Latina, 1980-2010. Alpha, 39, 189-202.

Canales Tapia, Pedro y Rea Campos, Carmen (eds.) (2013). Claro de luz: descolonización e «intelectualidades indígenas» en Abya-Yala, siglos XX-XXI. Santiago de Chile: Instituto de Estudios Avanzados.

Capredon, Elise (2018). Derrota interna, sucesso exterior: a patrimonialização do xamanismo entre os Baniwa (Alto Rio Negro - Amazonas). Horizontes Antropológicos, 24(51), 105-134.

Castillo Torres, Daniel Enrique (2013). «Pintando en Shipibo» - El arte de Cantagallo en Lima desde un contexto sociocultural: los casos de Elena Valera, Roldán 
Pinedo y los hermanos Guímer y Rusber García. Tesis de maestría, Pontificia Universidad Católica del Perú.

Castillo Torres, Daniel Enrique (2015). Arte y cultura en la pintura amazónica contemporánea: «El Búho» de Guímer García. Index-Revista de Arte Contemporáneo, 00, 32-40.

Chaumeil, Jean-Pierre (2009). El comercio de la cultura: el caso de los pueblos amazónicos. Bulletin de l'Institut Français d'Études Andines [en línea], 38(1), 61-74. Recuperado de http://journals.openedition.org/bifea/2822

Chirif, Alberto y García Hierro, Pedro (2007). Marcando territorio: progresos y limitaciones de la titulación de territorios indígenas en la Amazonía. Copenhague: IWGIA.

Cisler, Steven (2000). Introduction: The Internet and Indigenous Groups. Cultural Survival Quarterly Magazine, March Issue. Consultado julio de 2019. Recuperado de https:/www.culturalsurvival.org/publications/cultural-survival-quarterly/introduction-internet-and-indigenous-groups

Conklin, Beth (2002). Shamans versus Pirates in the Amazonian Treasure Chest. American Anthropologist, 104(4), 1050-1061.

Cortés Garzón, Liliana (2015). Amazónicos: un estudio de pintores amazónicos actuales. Tesis de doctorado, Universidad Autónoma de Barcelona.

Echeverri, Juan Álvaro y Romero Cruz, Isabel Victoria (2016). Agonía y revitalización de una lengua y un pueblo: los nonuya del Amazonas. Forma y Función [en línea], 29(1), 135-156.

Erikson, Philippe (2011). La patrimonialización de los cantos chamánicos chacobo. En Jean-Pierre Chaumeil, Óscar Espinosa de Rivero y Manuel Cornejo Chaparro (eds.), Por donde hay soplo: estudios amazónicos en los países andinos (pp. 491-501). Lima: IFEA/PUCP/CAAAP/EREA-LESC.

Espinosa, Oscar. 1998). Los pueblos indígenas de la Amazonía peruana y el uso político de los medios de comunicación. América Latina Hoy, 19, 91-100.

Espinosa, Oscar (2007). Para vivir mejor: los indígenas amazónicos y su acceso a la educación superior en Perú. Artículo, 3, 87-116.

Espinosa, Oscar (2009). Ciudad e identidad cultural: ¿cómo se relacionan con lo urbano los indígenas amazónicos peruanos en el siglo XXI? Bulletin de l'Institute Français d'Études Andines, 38(1), 47-59.

Espinosa, Oscar (2012). To Be Shipibo Nowadays: The Shipibo-Konibo Youth Organizations as a Strategy for Dealing with Cultural Change in the Peruvian Amazon Region. The Journal of Latin American and Caribbean Anthropology, 17(3), 451-471. 
Facundes, Sidney da S., Virtanen, Pirjo Kristiina, de Freitas, Marília Fernanda P., LimaPadovani, Bruna Fernanda S. y do Nascimento Costa, Patrícia (2018). Language Revitalization and Engagements in the Amazon: The Case of Apurinã. En S.D. Brunn y R. Kehrein (eds.), Handbook of the Changing World Language Map. Springer. https://doi.org/10.1007/978-3-319-73400-2_35-1

Fausto, Carlos y Emmanuel de Vienne (2014). Acting Translation: Ritual and Prophetism in Twenty-first-century Indigenous Amazonia. HAU: Journal of Ethnographic Theory, 4(2), 161-191.

Fernandes Correa, Alexandre (2011). Ação cultural, fixação identitária e excessos da patrimonialização. Ponencia presentada ante el Seminário Linguagem e Identidades: múltiplos olhares; III Encontro de Estudos Culturais; Sào Luis, 16-18 noviembre de 2011.

Fernández, Blanca S. (2010). ¿Quiénes son los intelectuales indígenas ecuatorianos?: aportes para una construcción intercultural de saberes en América Latina. $A$ Parte Rei-Revista de Filosofia, 71, 1-11.

Fernández-Llamazares, Álvaro (2015). Indigenous Knowledge of a Changing Environment: An Ethnoecological Perspective from Bolivian Amazonia. Barcelona: ICTA/UAB.

Fernández-Llamazares, Álvaro; Díaz-Reviriego, Isabel; Guèze, Maximilien; Cabeza, Mar; Pyhälä, Aili y Reyes-García, Victoria (2016). Local Perceptions as a Guide for the Sustainable Management of Natural Resources: Empirical Evidence from a Small-scale Society in Bolivian Amazonia. Ecology and Society [en línea], 21(1), 2. Recuperado de https://www.ecologyandsociety.org/vol21/iss1/art2/

Flores Carlos, Alejandra (2011). Intelectuales indígenas ecuatorianos y sistema educativo formal: entre la reproducción y la resistencia. Revista ISEES, 9, 21-39.

Fluehr-Lobban, Carolyn (2008). Collaborative Anthropology as Twenty-first-century Ethical Anthropology. Collaborative Anthropologies, 1, 175-182.

Gómez Rendón, Jorge (2008). Patrimonio lingüístico, revitalización y documentación de lenguas amenazadas. Revista Nacional de Cultura del Ecuador, 13, 35-49.

González, Jesús Manuel (1997). Indian City: To Be Urban and Indian in Venezuela; Assimilation or Cultural Reaffirmation? Abya Yala News, 10(3), 1-5.

High, Casey (2015). Victims and Warriors: Violence, History, and Memory in Amazonia. Urbana: University of Illinois Press.

IBGE (2010). Censo demográfico 2010 - População indígena: pirâmide étaria. Instituto Brasileiro de Geografía e Estatística. Recuperado de https://indigenas.ibge.gov. br/piramide-etaria-2.html

Inoach Shawit, Gil (2021). Entre la dependencia y la libertad: siempre awajún. Lima: Equidad/Fundación Nia Tero/IWGIA. 
IPCC (2019). Special Report on Climate Change, Desertification, Land Degradation, Sustainable Land Management, Food Security, and Greenhouse Gas Fluxes in Terrestrial Ecosystems. Intergovernmental Panel on Climate Change. Documento electrónico; consultado julio 2019. Recuperado de https://www.ipcc.ch/ site/assets/uploads/2019/08/4.-SPM_Approved_Microsite_FINAL.pdf

Jaramillo, Roberto (2003). Indiens urbains: processus de reconformation de l'identité ethnique indienne à Manaus. Tesis de doctorado, École des Hautes Études en Sciences Sociales.

Kopenawa, Davi y Albert, Bruce (2010). La chute du ciel: paroles d'un chaman yanomami. Paris: Plon.

Kopenawa, Davi y Albert, Bruce (2013). The Falling Sky: Words of a Yanomami Shaman. Cambridge: Harvard University Press.

Kronik, Jakob y Verner, Dorte (2010). Indigenous Peoples and Climate Change in Latin America and the Caribbean. Washington, D.C.: The World Bank.

Landolt, Gredna (2000). El ojo verde: cosmovisiones amazónicas. Lima: Fundación Telefónica.

Langdon, Esther Jean (2013). New Perspectives of Shamanism in Brazil: Shamanisms and Neo-Shamanisms as Dialogical Categories. Civilisations [en línea], 61(2), 19-35. Recuperado de http://journals.openedition.org/

Langdon, Esther Jean (2016). The Revitalization of Yajé Shamanism among the Siona: Strategies of Survival in Historical Context. Anthropology of Consciousness, 27(2), 180-203.

Lasmar, Cristiane (2005). De volta ao Lago de Leite: gênero e transformação no Alto Rio Negro. São Paulo: UNESP/ISA.

Lassiter, Luke Eric (2005a). Collaborative Ethnography and Public Anthropology. Current Anthropology, 46(1), 83-106.

Lassiter, Luke Eric (2005b). The Chicago Guide to Collaborative Ethnography. Chicago: Chicago University Press.

Leite, Flávia (2014). Online Technologies and the Struggle against Dam Building in the Amazon. Tipiti: Journal of the Society for the Anthropology of Lowland South America, 12(2), 122-127.

Loures de Assis, Glauber y Alves Rodrigues, Jacqueline (2017). De quem é a ayahuasca?: Notas sobre a patrimonialização de uma «bebida sagrada» amazónica. Religião e Sociedade, 37(3), 46-70.

Macdonald, Theodore (2010). Amazonian Indigenous Views on the State: A Place for Corporate Responsibility? Suffolk Transnational Law Review, Symposium, 3, 33. 
Macera, Pablo (2001). Lágrimas del piri-piri: pinturas y esculturas de la selva. Lima: Biblioteca Nacional.

Matos, Beatriz y Belaunde, Luisa Elvira (2014). Arte y transformación: experiencias e imágenes de los artistas de la Exposición «¡Mira!». Mundo Amazónico, 5, 297-308

Mayor Aparicio, Pedro y Bodmer, Richard E. (2009). Pueblos indígenas de la Amazonía peruana. Iquitos: Centro de Estudios Teológicos de la Amazonía.

McKibben, Bill (2019). Falter: Has the Human Game Begun to Play Itself Out? Henry Holt.

McSweeney, Kendra y Kokisch, Brad (2007). Beyond Rainforests: Urbanisation and Emigration among Lowland Indigenous Societies in Latin America. Bulletin of Latin American Research, 26(2), 159-180.

Meneses Tutaya, Norma (2013). La intelectualidad indígena y su rol en la revitalización cultural y lingüística de sus pueblos. Revista de Lengua y Sociedad, 13(1), 85-98.

Menton, M.C. (2003). Effects of Logging on Non-timber Forest Product Extraction in the Brazilian Amazon: Community Perceptions of Change. The International Forestry Review, 5(2), 97-105.

Micarelli, Giovanna (2015). «Divine Banknote»: The Translation of Project Money into Public Wealth. En Fernando Santos Granero (ed.), Images of Public Wealth or the Anatomy of Well-being in Indigenous Amazonia (pp. 161-190). Tucson: The University of Arizona Press.

Monroy-Álvarez, Silvia (2008). Sobre intelectuales y activistas indígenas: dos trayectorias interculturales posibles. Universitas Humanística, 66, 301-323.

Monsonyi, Esteban Emilio y Pocaterra González, Jorge (2004). Experiencias recientes de revitalización lingüística en la Venezuela indígena. Diàlegs - Fòrum Universal de les Cultures - Barcelona. Documento electrónico; consultado julio de 2019. Recuperado de http://www.barcelona2004.org/www.barcelona2004.org/ esp/banco_del_conocimiento/docs/PO_35_ES_POCATERRA.pdf

Nahum-Claudel, Chloé; Pétesch, Nathalie y Yvinec, Cédric (2017). Pourquoi filmer sa culture? Rituel et patrimonialisation en Amazonie brésilienne. Journal de la Société des Américanistes, 103(2), 47-80.

Okamoto Mendoza, Tami (2011). Enclave Extraction and Unruly Engagements: Oil Spills, Contamination and the Cocama-Cocamilla Indigenous People in the Peruvian Amazon. Tesis de maestría, Norwegian University of Life Sciences.

Ortiz, Diego (2015). El «millennial» tiene otra visión como indígena. El Comercio (Ecuador), 12 de julio de 2015. Recuperado de https:/www.elcomercio.com/ tendencias/millennial-vision-indigena-ecuador-intercultural.html 
Ortiz-Rodríguez, María de las Mercedes (2015). Interpelando a la nación brasilera: $O$ banquete dos deuses del escritor indígena Daniel Munduruku. Manguaré, 29(1), 75-101.

Pacheco de Oliveira, Bruno (2017). Juventude indígena: fluidez e experimentação. En Assis da Costa Oliveira y Lucia Helena Rangel (orgs.), Juventudes indigenas: estudos interdisciplinares, saberes interculturais. Conexões entre Brasil e México (pp. 160-175). Rio de Janeiro: E-papers Serviços Editoriais Ltda.

Pataxó, Kâhu (2017). Os desafios de ser uma liderança jovem indigena. En Assis da Costa Oliveira y Lucia Helena Rangel (orgs.), Juventudes indigenas: estudos interdisciplinares, saberes interculturais. Conexões entre Brasil e México (pp. 154-159). Rio de Janeiro: E-papers Serviços Editoriais Ltda.

Pelegrino de Mattos, Amilton (2015). Lecciones de la investigación indígena: el MAHKU - Movimiento de los Artistas Huni Kuin. Index-Revista de Arte Contemporáneo, 00, 88-95.

Peluso, Daniela M. (2015). Dossier: Indigenous Urbanization: The Circulation of Peoples Between Rural and Urban Amazonian Spaces. Journal of Latin American and Caribbean Anthropology, 20(1), 1-86.

Peluso, Daniela M. y Alexiades, Miguel N. (2005). Indigenous Urbanization and Amazonia's Post-Traditional Environmental Economy. Traditional Dwellings and Settlements Review, 16(2), 7-16.

Peña Márquez, Juan Carlos (2011). Mitú: ciudad amazónica, territorialidad indígena. Leticia: Universidad Nacional de Colombia.

Plaza Martínez, Pedro (2012). Tabuybula «nuestra lengua»: la enseñanza del yuracaré como segunda lengua en un programa de revitalización lingüística y cultural. Proceedings of the Symposium on Teaching and Learning Indigenous Languages of Latin America (STLILLA 2011). Documento electrónico; consultado julio 2019. Recuperado de https://www.academia.edu/5101008/Tabuybula_yuracare

Plotkin, Mark J. (2009). Changing the Landscape of Power. Innovations: Technology, Governance, Globalization, 4(2), 13-25.

Ponce, Patricia, Rubén Muñoz y Stival, Matías (2017). Pueblos indígenas, VIH y políticas públicas en Latinoamérica: una exploración en el panorama actual de la prevalencia epidemiológica, la prevención, la atención y el seguimiento oportuno. Salud Colectiva, 13(3), 537-554. Recuperado de https://www.scielosp. org/pdf/scol/2017.v13n3/537-554/es

Rappaport, Joanne (2008). Beyond Participant Observation: Collaborative Ethnography as Theoretical Innovation. Collaborative Anthropologies, 1, 1-31.

Renshaw, John y Wray, Natalia (2004). Indicadores de bienestar y pobreza indígena. Documento electrónico; consultado en julio de 2019. Recuperado de file://C:/ 
Users/santosf/Documents/Articulos.colegas/Renshaw,\%20John/2004.Renshaw $\% 20 y \% 20$ Wray,Indicadores $\% 20 \mathrm{de} \% 20$ Bienestar\%20\&\%20Pobreza $\% 20$ Indigena.pdf

Rojas Torres, Karen Elizabeth (2016). Desarrollo de una plataforma web educativa para la revitalización de la lengua kukama-kukamiria de Perú. Tesis de maestría, Universidad Politécnica de Valencia.

Romero Cruz, Isabel Victoria (2015). Acompañamiento al proceso de revitalización de la lengua nonuya: un caso de lucha por la supervivencia lingüistica. Tesis de maestría, Universidad de Colombia.

Sánchez, Luisa Fernanda (2010). Paisanos en Bogotá: identidad étnica y migración indígena amazónica. En Margarita Chaves y Carlos del Cairo (eds.), Perspectivas antropológicas sobre la Amazonía contemporánea (pp. 129-152). Bogotá: Instituto Colombiano de Antropología e Historia y Pontificia Universidad Javeriana.

Santos Granero, Fernando (1996). Introducción: Hacia una antropología de lo contemporáneo en la amazonía indígena. En Fernando Santos Granero (comp.), Globalización y cambio en la Amazonía indígena (pp. 7-46). Quito: Abya-Yala.

Santos Granero, Fernando (2007). Prólogo. En Alberto Chirif y Pedro García Hierro (eds.), Marcando territorio: progresos y limitaciones de la titulación de territorios indigenas en la amazonía (pp. 12-17). Copenhague: IWGIA.

Santos Granero, Fernando (2017). Patrimonialization, Defilement and the Zombification of Cultural Heritage. Nuevo Mundo Mundos Nuevos [en línea]. Recuperado de http://journals.openedition.org/nuevomundo/70152

Santos Granero y Fabiano, Emanuele (orgs.) (2019). Urban Imaginaries in Native Amazonia: Tales of Alterity, Power, and Defiance. Simposio presentado ante la XII Conferencia Sesquianual de la Society for the Anthropology of Lowland South America, Vienna, 27-30 de junio.

Santos Granero, Fernando y Barclay, Frederica (2010). Bultos, selladores y gringos alados: percepciones indígenas de la violencia capitalista en la Amazonía peruana. Anthropologica, 28(1), 21-52.

Schwab, Klaus (2016). The Fourth Industrial Revolution. Geneva: World Economic Forum.

Shulist, Sarah (2013). In the House of Transformation: Language Revitalization, State Regulation, and Indigenous Identity in Urban Amazonia. Tesis de doctorado, The University of Western Ontario.

Shulist, Sarah (2015). «Graduated Authenticity»: Multilingualism, Revitalization, and Identity in the Northwest Amazon. Language \& Communication, 47, 112-123. 
Shulist, Sarah (2016). Indigenous Names, Revitalization Politics, and Regimes of Recognition in the Northwest Amazon. The Journal of Latin American and Caribbean Anthropology, 21(2), 336-354.

Simpson, Tony (1997). Patrimonio indígena y autodeterminación. Copenhague: Documentos IWGIA N 22.

Soria, María Belén (1998). Llanchamas bora: Victor Churay Roque. Lima: Museo del Banco Central de Reserva del Perú.

Soria, María Belén (2001). Arte shipibo: Roldán Pinedo y Elena Valera (pintores). Lima: Seminario de Historia Rural Andina, Universidad Nacional Mayor de San Marcos.

Soria, María Belén y Casanto, Enrique (2002). Arte y cultura del monte. Lima: Seminario de Historia Rural Andina, Universidad Nacional Mayor de San Marcos.

Steele, Diana (2018). Higher Education and Urban Migration for Community Resilience: Indigenous Amazonian Youth Promoting Place-Based Livelihoods and Identities in Peru. Anthropology \& Education Quarterly, 49(1), 89-105.

Surrallés, Alexandre (2009). Entre derecho y realidad: antropología y territorios indígenas amazónicos en un futuro próximo. Bulletin de l'Institute Français d'Études Andines, 38(1), 29-45.

Swing, Kelly; Davidov, Veronica y Schwartz, Brendan (2012). Oil Development on Traditional Lands of Indigenous Peoples: Coinciding Perceptions on Two Continents. Journal of Developing Societies, 28(2), 257-280.

Tangarife, Hugo; Ceballos, Luis y Rodríguez, Jorge (2018). Chamanismo, enteógenos y arte contemporáneo. Cultura y Droga, 23(25), 106-136.

Valenzuela, Pilar M. (2010). Ethnic-racial Reclassification and Language Revitalization among the Shiwilu from Peruvian Amazonia. International Journal of the Sociology of Language, 202, 117-130.

Vega Díaz, Ismael (2014). Buscando el río: identidad, transformaciones y estrategias de los migrantes indígenas amazónicos en Lima Metropolitana. Lima: Terra Nuova/Centro Amazónico de Antropología y Aplicación Práctica.

Vienne, Emmanuel de y Allard, Olivier (2005). Pour une poignée de dollars? Transmission et patrimonialisation de la culture chez les Trumai du Brésil central. Cahiers des Amériques Latines [en línea], 48-49, 127-145. Recuperado de http:// cal.revues.org/7907

Virtanen, Pirjo Kristiina (2006). The Urban Manchinery Youth and Social Capital in Western Amazonian Contemporary Rituals. Anthropos, 101(1), 159-167. 
Virtanen, Pirjo Kristiina (2009a). Global Youth Cultures and Amazonian Indigenous Adolescence. Documento electrónico, consultado en julio de 2019. Recuperado de https://www.sylff.org/wp-content/uploads/2009/03/virtanen.pdf

Virtanen, Pirjo Kristiina (2009b). Shamanism and Indigenous Youthhood in the Brazilian Amazon. Amazônica, 1(1), 152-177.

Virtanen, Pirjo Kristiina (2010). Amazonian Native Youths and Notions of Indigeneity in Urban Areas. Identities, 17(2), 154-175.

Virtanen, Pirjo Kristiina (2012). Indigenous Youth in Brazilian Amazonia: Changing Lived Worlds. New York: Palgrave Macmillan.

Virtanen, Pirjo Kristiina (2015). Indigenous Social Media Practices in Southwestern Amazonia: Digital Exchanges. Alternative, 11(4), 350-362.

Viveiros de Castro, Eduardo (1998). Cosmological Deixis and Amerindian Perspectivism. Journal of the Royal Anthropological Institute, 4(3), 469-488.

Walker, Harry (2019). Fragile Time: The Redemptive Force of the Urarina Apocalypse: Indigenous Perceptions of the End of the World. En Rosalyn Bold (ed.), Indigenous Perceptions of the End of the World: Creating a Cosmopolitics of Change (pp. 51-69). Palgrave: Macmillan.

Wallace-Wells, David (2019). The Uninhabitable Earth: Life after Warming. Tim Duggan Books.

Wei, Clarissa (2017). Cómo vive un indígena millennial en la selva amazónica. Newsletter Vice. Recuperado de https:/www.vice.com/es_latam/article/pgzpdm/ como-vive-un-indigena-millennial-en-la-selva-amazonica

Wright, Robin M. (2013). Mysteries of the Jaguar Shamans of the Northwest Amazon. Lincoln: University of Nebraska Press.

Wroblewski, Michael (2014). Public Indigeneity, Language Revitalization, and Intercultural Planning in a Native Amazonian Beauty Pageant. American Anthropologist, $116(1), 65-80$.

Xu, Min, Jeanne M. David y Kim Hi, Suk (2018). The Fourth Industrial Revolution: Opportunities and Challenges. International Journal of Financial Research, 9(2). Documento electrónico; consultado julio de 2019. Recuperado de http:// www.sciedupress.com/journal/index.php/ijfr/article/view/13194/8136

Yllia, María Eugenia (2009). De la maloca a la galería: la pintura sobre llanchama de los boras y huitotos de la Amazonía peruana. Illapa, 6(6), 95-107.

Yllia, María Eugenia (2011). Transformación e identidad en la estética amazónica: la pintura sobre llanchama del artista bora Víctor Churay Roque. Tesis de licenciatura, Universidad Nacional Mayor de San Marcos. 